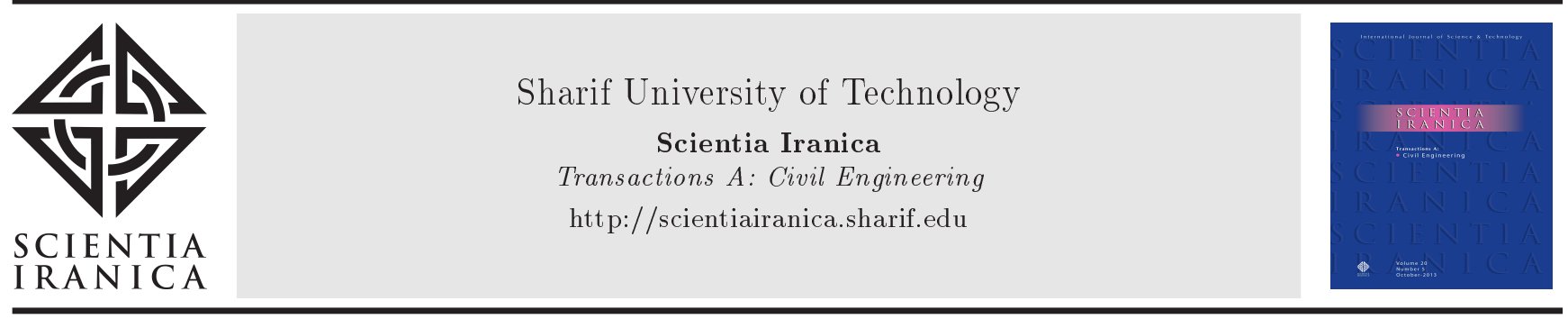

\title{
Soil behavior around the stub abutment of an integral bridge and buried piles in the contraction state
}

\author{
M. Barghian, S. Khaki Khatibi*, and M. Hajialilue-Bonab \\ Department of Civil Engineering, Faculty of Engineering, University of Tabriz, Tabriz, P.O. Box 51666-14171, Iran.
}

Received 28 June 2017; received in revised form 12 November 2017; accepted 6 June 2018

\section{KEYWORDS}

Soil behavior;

Stub abutment;

Integral bridge;

Buried piles;

Soil-structure

interaction.

\begin{abstract}
A change in the deck length under temperature load affects the upper part of integral bridge abutments and causes abutment rotation. The deck contraction makes the abutment move away from the backfill and causes wedge failure. To prevent wedge failure, a new method has been proposed. In this method, the inhibition of integral bridges under contraction is done by cables connected from each abutment to the buried piles outside the bridge along the abutments. In the analysis, the behavior of soil around the abutment and buried piles is an important parameter that has great influence on the results. In this paper, the soil behavior around a laterally loaded stub abutment and buried piles was studied by laboratory stub abutment models using the PIV (Particle Image Velocimetry) method. The PIV analysis was carried out to obtain the deformation pattern and shear strains of the soil around the stub abutment and buried piles. The effects of piles number and soil-pile interaction on the soil deformation pattern were investigated. The results showed that the use of buried piles connected by the cable prevented wedge failure in the backfill.
\end{abstract}

(C) 2020 Sharif University of Technology. All rights reserved.

\section{Introduction}

Integral bridges are constructed without expansion joints. In these bridges, the deck is connected to abutments continuously. Thus, these bridges act as a rigid frame [1-5]. Reported by Cooke [6], the North American Study Tour Report presented several types of abutments: the full-height frame, embedded-wall abutments, spread footings on reinforced earth wall, vertical wall with semi-integral, and stub abutment. However, stub abutments were found to perform well [7]. In Figure 1, an integral bridge with a stub abutment is shown.

\footnotetext{
*. Corresponding author.

E-mail addresses: barghian@tabrizu.ac.ir (M. Barghian); saeedkhakikhatibi@yahoo.com (S. Khaki Khatibi); mhbonab@gmail.com (M. Hajialilue-Bonab)
}

This type of bridge has many advantages over conventional bridges. One important benefit of this type of bridge is the removal of expansion joints and bearings (which are expensive and need installation, maintenance, and repair problems) [8-10]. On the other hand, their deck length is increased or decreased due to seasonal temperature changes [1113]. Since integral bridges are of a continuous unit system, stresses are transferred from the bridge to the soil under the expansion and contraction caused by temperature changes. The amount of force generated in the backfill depends on the expansion and contraction of the bridge. The increasing or decreasing amount of the deck length is directly associated with backfill specifications. Therefore, the contraction or expansion of the bridge and the force created in the backfill are in interaction with each other [14]. The soil-structure interaction (the backfill and bridge substructure) causes a series of behavioral complications $[7,15]$. The major problem of integral bridges is related to geotechnical 


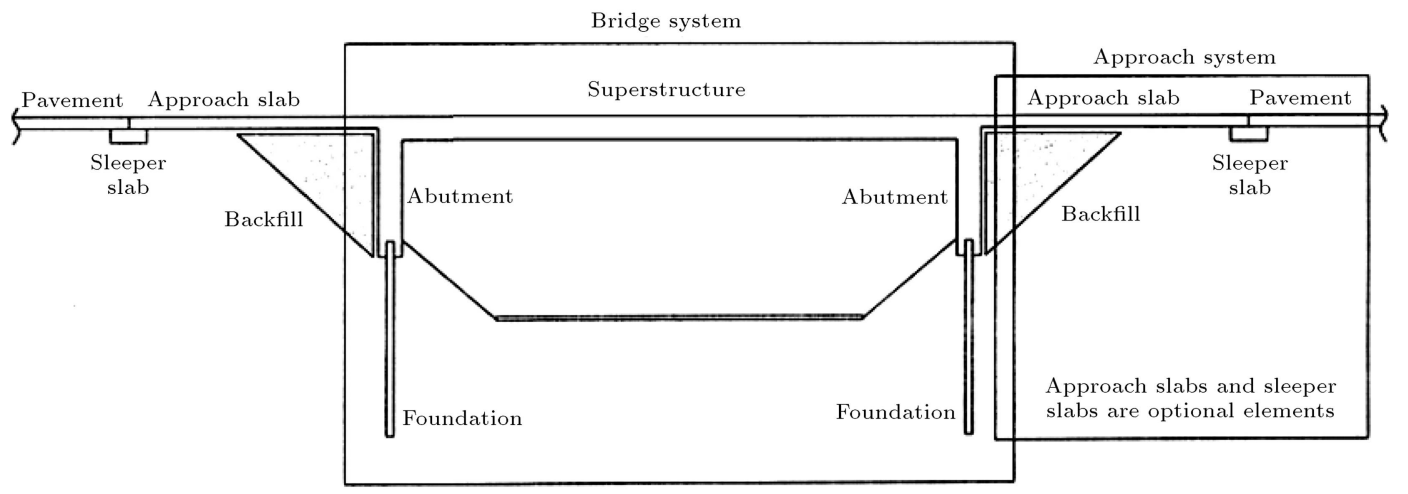

Figure 1. Stub-type integral abutment bridge [8].

issues. Figure $2[16]$ shows bridge expansion and contraction problems caused by temperature changes.

The deck contraction causes the abutment to move away from backfill and results in wedge failure. According to Eq. (1) [11], the deck expansion or contraction $(\Delta L)$ of an integral bridge depends on daily and seasonal temperature changes $(\Delta T)$, thermal expansion coefficient $(\alpha)$, and the initial length of the bridge $\left(L_{0}\right)$.

$$
\Delta L=\Delta T \cdot \alpha \cdot L_{0} .
$$

The expansion and contraction of the bridge under temperature load will be high when the length of the bridge increases. When the expansion and contraction of the bridge increase, abutment, deck, and the pile under the abutment withstand larger force beyond their capacity. It is surely not easy to predict this force due to the adjacency of the bridge to soil [17]. Zordan et al. [18] investigated a $2 \mathrm{D}$ simplified finite-element model of an actual 400-meter-long Integral Abutment Bridge (IAB), built in Italy. They considered the negative temperature variations (contraction of the bridge). Zordan et al. [19], in another paper, pointed out that achieving the maximum length attainable with an integral abutment bridge was intrinsically dependent on a thorough understanding of the soilstructure interaction behind the abutments.

The researches that have been conducted so far have attempted to solve the problems caused by the

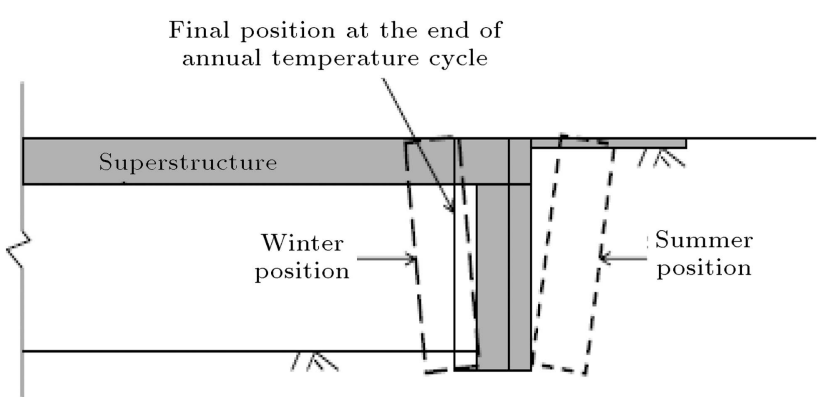

Figure 2. Thermally induced IAB abutment displacement [16]. expansion and contraction in the integral bridges. Researches have suggested different solutions. Mostly reported among those solutions are the changing of different variables such as the dimensions of the abutment and the deck as well as the changing of materials used in the bridge. Attempts have been made to obtain the optimum size of the bridge. For example, Kim and Laman [20] studied parametric analysis cases including backfill-abutment interaction and soil-pile interaction. Keisha et al. [21] studied a practical limit for the maximum length of pre-stressed concrete girder integral abutment bridges. They carried out a parametric study on a bridge with the length of $305 \mathrm{~m}$ considering the effects of abutment height, soil stiffness, and pile orientation on integral abutment bridge response. Their study suggested the maximum length of $457 \mathrm{~m}$ on the basis of critical responses of the integral abutment bridge. Kong et al. [22] investigated the thermal performance of Caminada Bay Bridge, which was built on soft soil conditions in 2011. Based on the parametric studies, the numerical modeling methodology for integral abutment bridge, such as temperature loadings, soil-abutment interactions, and soilpile interactions, is verified by comparing the bridge responses with those of the field study. The result of this study showed that the soils surrounding the piles have the most significant effects on the bridge responses. In addition, changing soft soils to stiff ones produces, at maximum, 1.5 times smaller bridge displacements. To prevent excessive and destructive transformations due to temperature changes, the length of integral bridges has been limited in most researches [17,2327]. However, it is sometimes necessary to construct longer integral bridges. One suggested solution to resolving the expansion of the integral bridge problem at greater lengths is the reduction of the abutment height in order to reduce the passive force in the backfill when the abutment moves towards the backfill (deck expansion) [28]. In a contraction case, the bridge abutment moves away from the backfill, and a separation (gap) between the abutment and the backfill occurs. To solve the separation (gap) problem, some 

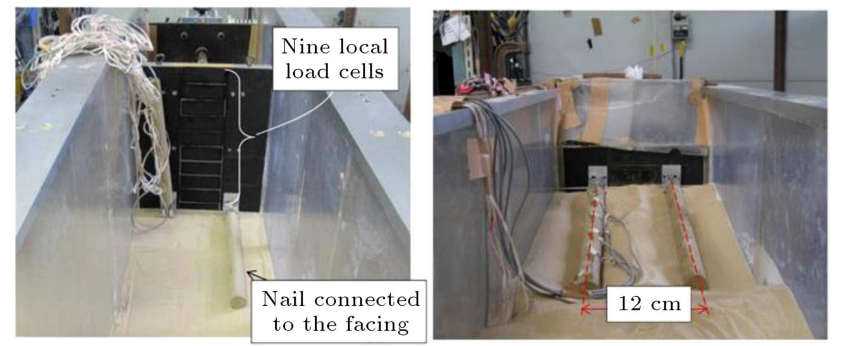

Figure 3. Static lateral loading tests of an abutment model with nails [29].

methods, such as nailing [29] and application of foams and geogrid [30,31], have been used to prevent the contraction of the integral bridge. The aim of the techniques, which have been used so far, was to keep the stability of soil under contraction. For example, Tatsuoka et al. [29] increased the stability of backfill by nailing the full height abutment to the backfill in a laboratory test. The image of this method is shown in Figure 3. Koseki et al. [30] and Tatsuoka et al. [31] increased the stability of the backfill by placing a geogrid in the backfill connected to the abutment in laboratory tests. However, these methods did not decrease the amount of contraction of the bridge and only increased the stability of the soil. According to the research by the above-mentioned authors, they have studied integral bridges with a full height abutment. Despite their effort, they could not reduce or prevent the contraction of the bridge considerably. Therefore, further research is required. The aim of the present study is to inhibit the integral bridge contraction with a stub abutment.

In the present research, a cable connection from the abutment to soil was proposed in order to provide a solution to control the contraction of the integral bridge with a stub abutment to prevent wedge failure in the backfill and to stabilize the soil. In this method, the connection is done in such a way that one end of the cable is connected to the abutment and the other side of the cable is connected to a buried pile, which is located at a certain distance from the abutment. By conducting different experiments in a laboratory, the success of the proposed method was evaluated. The distance of the pile from the abutment can be calculated in such a way that the pile location is far from the area of the active or passive wedge failure, during winter or summer. When the contraction of the abutment occurs, the pile is subjected to lateral force. Therefore, the interaction occurs between the pile and the neighboring soil. The interaction causes an opposite force on the abutment, preventing the contraction of the abutment. The image of this method is shown in Figure 4.

In the analysis of soil-pile interaction and soilstub abutment interaction under lateral load, the behavior of soil around a stub abutment and piles is an important parameter that has great influence on the results. In this paper, the soil behavior around the laterally loaded stub abutment and piles was studied through laboratory stub abutment models using the PIV (Particle Image Velocimetry) method.

\section{Physical modeling and scaling laws}

In this research, small physical scale modeling was implemented and, then, extended to a full scale. Thus, the appropriate scaling laws and dimensional analysis to control them seem to be necessary. The advantages of the small-scale laboratory modeling are as follows [32]: full control over the details of the model, the possibility of soil choice, the possibility of boundary conditions, model loading choice, the low volume of soil, the possibility of conducting more experiments, the possibility of studying the effects of changes in key variables and, finally, low cost in comparison with the costs of full-scale experiments.

The governing equation of the deformed pile under the lateral load can be written as follows [33]:

$$
E I \frac{d y^{4}}{d z^{4}}=-k y,
$$

where $E I, y, z$, and $k$ are the pile flexural rigidity, the horizontal displacement of the pile, the distance measured along the pile length, and the coefficient
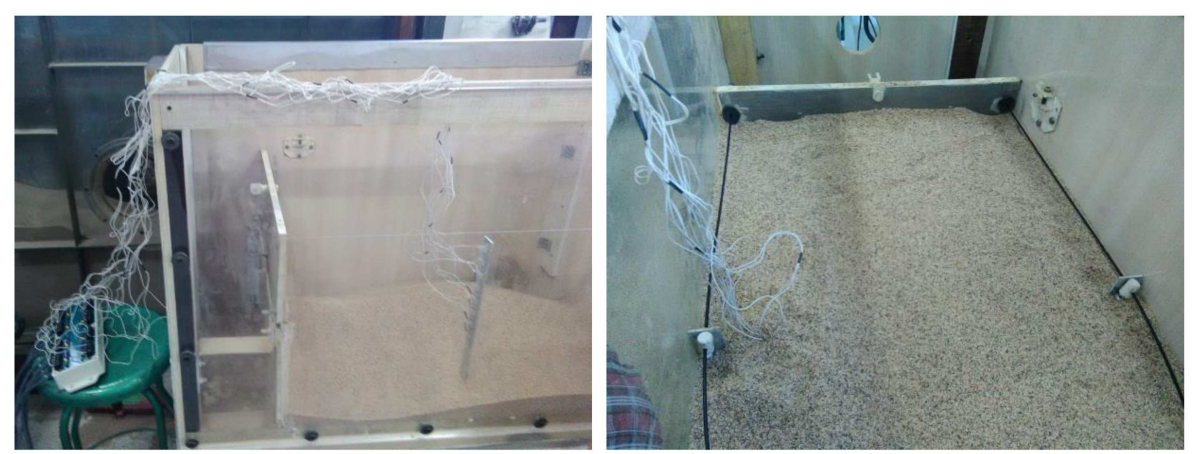

Figure 4. Static lateral loading tests of a stub abutment model in the present research. 


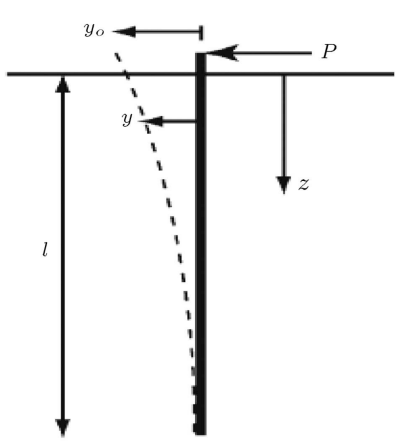

Figure 5. Pile under lateral loading.

of soil reaction, respectively. $k$ is proportional to the soil shear modulus $(G)$. To normalize Eq. (2), dimensionless coefficients according to Eq. (3) are defined as follows:

$$
\xi=\frac{Z}{L}, \quad \lambda=\frac{y}{y_{0}},
$$

where $\xi, L, \lambda$, and $y_{0}$ are the dimensionless depth term, pile length depth, pile dimensionless displacement, and the lateral displacement on the top of the pile, respectively. Thus, Eq. (2) can be rewritten as follows:

$$
\frac{E I}{L^{4}} \frac{d \lambda^{4}}{d \xi^{4}}=-k \lambda .
$$

$\phi_{1}=\frac{k L^{4}}{E I}$ is a suitable dimensionless variable to describe the relative stiffness of the pile and soil. It can be assumed that if dimensionless variable $\phi_{1}$ is the same for the model and the real size, then the physical model will be valid. Figure 5 shows the parameters of the above equations.

The scale factors of $n_{E}, n_{I}$, and $n_{k}$ are considered as the modulus of elasticity $E$, the inertia moment of the pile, and the coefficient of the soil reaction, respectively. By inserting the scale factors in $\phi_{1}$, we have:

$$
n_{E} \times n_{I}=n_{k} \times n_{l}^{4} .
$$

It is assumed that the length scale is $n_{l}=1 / n$, which leads to $n_{E} \times n_{I}=1 / n^{4+\alpha}$ for the single gravity experiment and $n_{E} \times n_{I}=1 / n^{4}$ for modeling a geotechnical centrifuge with a centrifugal acceleration of $n_{g}$, where parameter $\alpha$ is relevant to the scaling of soil stiffness in the geotechnical modeling.

In granular soils, the stiffness parameter of the subgrade changes linearly with respect to stress; therefore, $k=n_{h} \times Z$ where $n_{h}$ is a constant factor of the subgrade reaction. In this situation, the scale factor of soil stiffness $(\alpha)$ is about 1 . The dimensionless group for $1 g$ experiment can be assumed in granular soil. Thus, $\phi_{1}=n_{h} l^{5} / E I$. This results in $n_{E} \times n_{I}=1 / n^{5}$.

In the stub abutment physical modeling, if the width and height of the abutment are $B$ and $H$, respectively, then coefficients $\alpha$ and $\beta$ are defined as follows:

$$
\alpha=\frac{H}{L}, \quad \beta=\frac{B}{L} .
$$

Therefore, the width and height of the abutment on the full scale will be $\alpha L$ and $\beta L$, respectively. Since the stub abutment is located on one row of flexible piles, a spring steel plate was used for simulation.

For instance, for small-scale physical modeling, a stub abutment characterized by the height of $20 \mathrm{~cm}$ and the width of $50 \mathrm{~cm}$ and an aluminum pile $(E=$ $70 \mathrm{GPa}$ ) of $350 \mathrm{~mm}$ in length, $60 \mathrm{~mm}$ in width, and $3 \mathrm{~mm}$ in thickness, using a 1:15 scale version, will give a prototype model of a stub abutment with a height of $3 \mathrm{~m}$ and the width of $7.5 \mathrm{~m}$. In addition, a steel pile $(E=210 \mathrm{GPa})$ of $5.25 \mathrm{~m}$ in length and inertia moment of $3375 \mathrm{~cm}^{4}$ (e.g., IPE 600 ) provides the same behavior. The calculations are done and presented below:

$$
\frac{H_{m}}{H_{p}}=\frac{1}{n^{\prime}}, \quad \frac{W_{m}}{W_{p}}=\frac{1}{n} .
$$

If $\frac{1}{n}=\frac{1}{15}, H_{m}=20 \mathrm{~cm}$ and $W_{m}=50 \mathrm{~cm}$, then $H_{p}=$ $3 \mathrm{~m}, W_{p}=7.5 \mathrm{~m}$ where:

$H_{m} \quad$ The abutment height of the model

$H_{p} \quad$ The abutment height of the prototype

$W_{m} \quad$ Abutment width of the model

$W_{p} \quad$ Abutment width of the prototype

$1 / n \quad$ The scale factor

$$
n_{E} \times n_{I}=1 / n^{5} .
$$

If $\frac{1}{n}=\frac{1}{15}$ and $n_{E}=\frac{70}{210}$, then $n_{I}=4 \times 10^{-6}$.

$$
\frac{I_{m}}{I_{p}}=n_{I},
$$

where:

$I_{m} \quad$ Inertia moment of model pile;

$I_{p} \quad$ Inertia moment of prototype pile.

$$
I_{m}=1 / 12 \cdot b \cdot t^{3}
$$

If $b=60 \mathrm{~mm}$ and $t=3 \mathrm{~mm}$, then $I_{m}=135 \mathrm{~mm}^{4}$ where:

$b \quad$ Width of the model pile;

$t \quad$ Thickness of the model pile.

According to Eq. (8):

$$
I_{p}=\frac{I_{m}}{n_{I}}
$$

If $I_{m}=135 \mathrm{~mm}^{4}$ and $n_{I}=4 \times 10^{-6}$, then $I_{p}=$ $3375 \mathrm{~cm}^{4}$ (for example, IPE600).

$$
\frac{L_{m}}{L_{p}}=\frac{1}{n} \text {. }
$$

If $\frac{1}{n}=\frac{1}{15}$ and $L_{m}=350 \mathrm{~mm}$, then $L_{p}=5.25 \mathrm{~m}$, where: 
$L_{m} \quad$ Length of the model pile;

$L_{p} \quad$ Length of the prototype pile.

The details of the small-scale physical modeling are described in the following section.

\section{Test set-up}

\subsection{Specification of the experimental device}

The experimental device model includes a wooden box with interior dimensions of $110 \times 50 \times 80 \mathrm{~cm}^{3}(L$ : $110 \mathrm{~cm}, W: 50 \mathrm{~cm}$, and $H: 80 \mathrm{~cm})$. In order to prevent the deformation of the box under the lateral pressure of the soil, a seven-layer wood with the thickness of $16 \mathrm{~mm}$ was selected. In the front face of the tank, a transparent plexiglass characterized by the dimensions of $110 \times 80 \mathrm{~cm}^{2}$ and a thickness of $20 \mathrm{~mm}$ was used in order to observe deformation in the soil. For modeling, a stub abutment of integral bridge was constructed within a rigid retaining wall box characterized by the width and height of $50 \mathrm{~cm}$ and $20 \mathrm{~cm}$, respectively. The wall was connected to a fixed support with a width of $50 \mathrm{~cm}$ and a height of $30 \mathrm{~cm}$. On the full scale of integral bridges with the stub abutment, the abutment bridge was placed over a row of flexible piles so that the abutment could rotate over these piles under the expansion and contraction of the deck.

To simulate this behavior in an experimental model, for connection between the abutment and the support, a flexible spring steel plate was used with a length of $50 \mathrm{~cm}$ and a height of $1.5 \mathrm{~cm}$. Hence, the abutment was connected to the plate, and the plate was connected to the support. By a construction method, the abutment can rotate on the spring plate by a specific horizontal force. The specifications of the spring steel plate are given in Section 3.3.

To apply the horizontal displacement caused by the contraction of the deck, a fixed speed electro motor was used. The force was applied to the retaining wall (i.e., on the stub abutment of the integral bridge) by a lever.

Figures 6 and 7 represent the mechanism for lab tests and the lab environment, respectively. To record the amount of lateral displacement of the abutment and the amount of applied lateral force, the LVDT and load cell were used, respectively. In this model, the

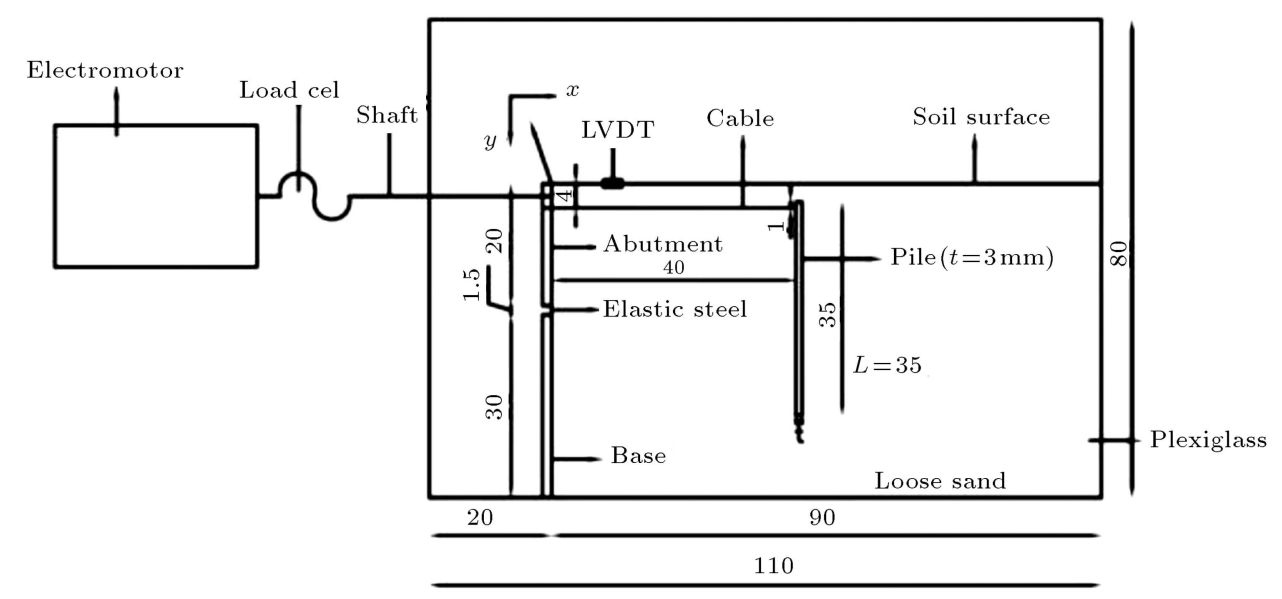

(a)

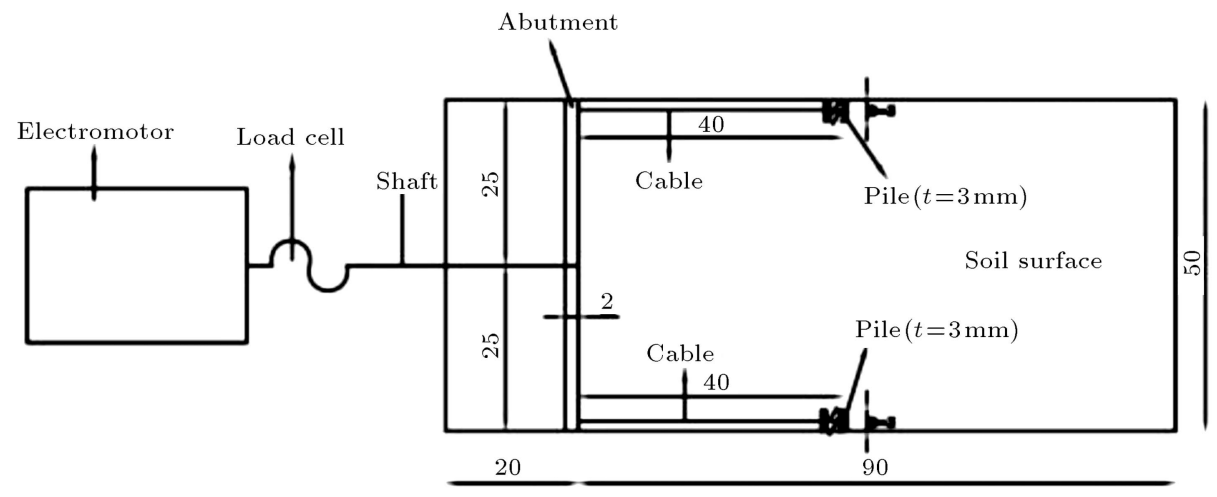

(b)

Figure 6. Schematic view of test setup: (a) Front view and (b) top view (all units in $\mathrm{cm}$ ). 

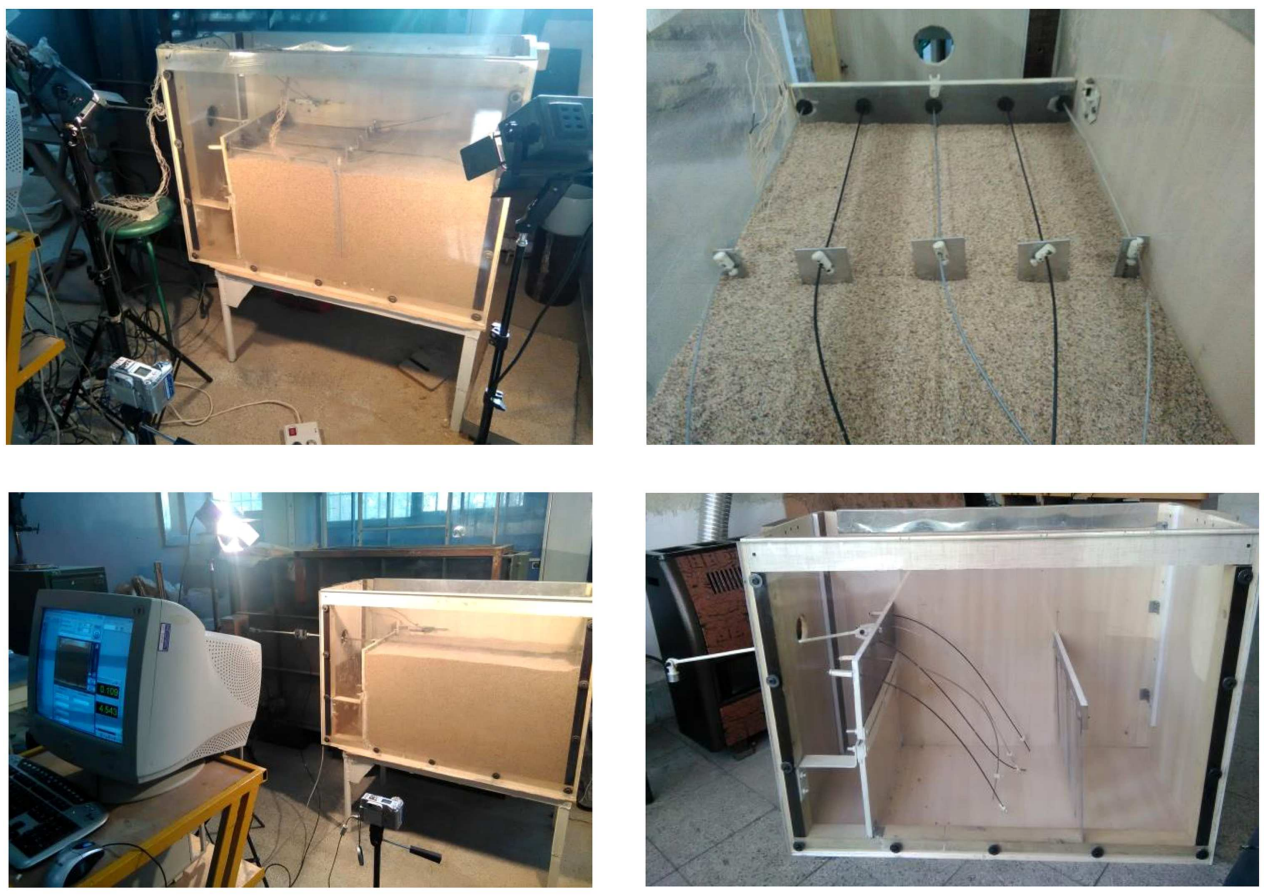

Figure 7. General view of the laboratory model apparatus.

data from measurement devices were stored by a data acquisition system (i.e., the data logger).

As seen in Figures 6 and 7, each pile is connected by a cable to the wall (i.e., the integral bridge abutment).

\subsection{Soil}

For evaluation, Firoozkooh dry sand, located in Tehran, was used. The soil gradation curve graph and the test sand specifications are provided in Figure 8 and Table 1, respectively.

\subsection{Pile, cable, spring steel}

In this study, a tall pile was used for the test for which the theoretical definition is given by Eq. (11):

$$
\frac{L}{T} \geq 4, \quad T=\sqrt[5]{\frac{E I}{n_{h}}},
$$

where $L, T$, and $E I$ are the embedded length of the pile, length coefficient, flexural stiffness, respectively. In addition, $n_{h}$ is the constant modulus of subgrade horizontal reaction, which was considered as $2 \mathrm{MN} / \mathrm{m}^{3}$, experimentally in this project. Since the piles with

Table 1. Specifications of sand.

\begin{tabular}{ll}
\hline Unit weight $(\gamma)$ & $15\left(\mathrm{kN} / \mathrm{m}^{3}\right)$ \\
Friction angle $(\phi)$ & $36.3(\mathrm{deg})$ \\
Cohesion $(C)$ & $0\left(\mathrm{kN} / \mathrm{m}^{3}\right)$ \\
Specific gravity $\left(G_{S}\right)$ & 2.62 \\
Subgrade horizontal reaction & $2\left(\mathrm{MN} / \mathrm{m}^{3}\right)$ \\
constant module $\left(n_{h}\right)$ & \\
\hline
\end{tabular}

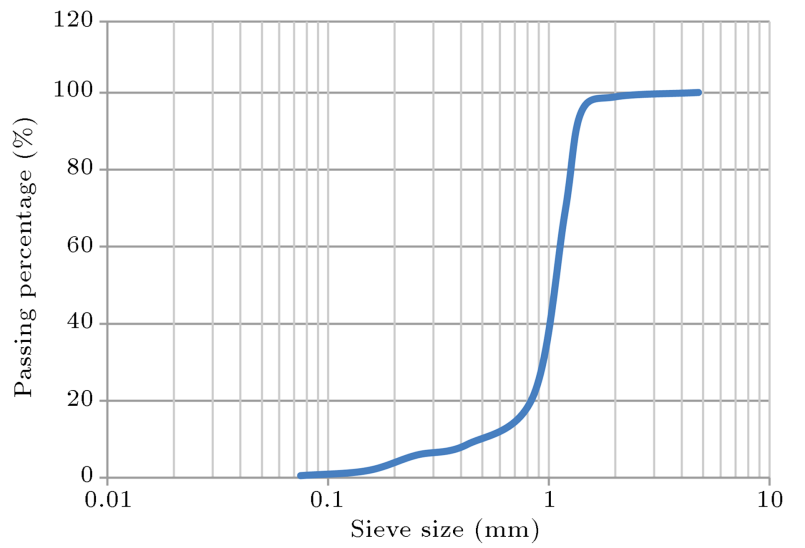

Figure 8. Particle size distribution.

rectangular sections (small thickness with respect to width) enjoy lower rigidity, the rectangular sections were selected in order to conduct a better evaluation of the piles behavior. The pile was placed adjacent to the plexiglass such that the small width of the pile section (i.e., in the weak axis direction) faced the front of the glass plate. The characteristics of the plies are given in Table 2 .

In this study, due to their low flexural stiffness, cables were connected to the pile(s) from the abutment. Cables' properties are shown in Table 3. In Table 3, the lay direction indicates the direction in which the outer wires (outer strands) of the strand (cable) are laid around the center wire (core strand). In addition, "S-lay-left" means that the outer wires (outer strands) are laid in the left direction around the center wire (core strand). 
Table 2. Model pile properties.

\begin{tabular}{ll}
\hline Length, $L(\mathrm{~mm})$ & 350 \\
Breadth, $B(\mathrm{~mm})$ & 60 \\
Thickness, $t(\mathrm{~mm})$ & 3 \\
$E I\left(\mathrm{~N} \cdot \mathrm{m}^{2}\right)$ & 9.315 \\
$L / T$ & 4.17 \\
Material & Aluminum \\
\hline
\end{tabular}

Table 3. Cable properties.

\begin{tabular}{ll}
\hline Diameter & $2.5(\mathrm{~mm})$ \\
Lay direction & S-lay-left \\
Elastic modulus, $E$ & $199(\mathrm{GPa})$ \\
Tensional stress rang, Fu & $1400(\mathrm{MPa})$ \\
\hline
\end{tabular}

Table 4. Spring steel properties.

\begin{tabular}{ll}
\hline Width & $500(\mathrm{~mm})$ \\
Height & $15(\mathrm{~mm})$ \\
Thickness & $1(\mathrm{~mm})$ \\
Elastic modulus, $E$ & $200(\mathrm{GPa})$ \\
Yield stress, $\sigma_{y}$ & $1200(\mathrm{MPa})$ \\
Carbon percentage & $1.6 \%$ \\
\hline
\end{tabular}

In this study, the spring steel was used to simulate the abutments rotation. This plate was located vertically between the abutment and support in order to connect the abutment and support to each other. The properties of the spring steel plate are given in Table 4.

\subsection{Image analysis by the PIV method}

Two Cannon G6 (7.2 megapixels) cameras were used for the purpose of photographing soil displacements during the test. The cameras were set up in front and top of the device. All operations, such as focusing, gaining, and shutter speed, were done automatically by the Remote Capture Software. Two 1000-Watt lightening projectors were used to provide the environments with light. Those projectors were deployed at 45-degree angles over the set.

The Geo PIV software was used to analyze the screens [34]. In this software, the images were meshed with a series of patches, and the center of each patch was selected. By calculating central location changes, the displacement vectors of the soil were extracted.

The soil displacements are extracted within an image space (units of pixels). Therefore, units need to be converted to centimeters. Using calibration techniques, the amount of the soil displacement is converted from pixels to centimeter. This was undertaken by using two marker dots on the transparent window. As the positions of the markers in the transparent window do not change between images, it is possible to extract calibration factors to convert the image displacements (in pixel unit) and real displacements (in centimeter unit) for the markers.

In the Geo PIV software, the PIV analysis was done using patches of $32 \times 32$ pixels, spaced at 32 -pixel centers, and a search area of $64 \times 64$ pixels.

\section{Procedure of the experiment}

In the present research, in order to apply the horizontal displacement - caused by the contraction of the deck an electro motor with fixed speed was used. The force was applied on the head of the stub abutment by a lever. It was applied from right to left (towards to the electromotor as shown in Figure 6(a)) in the tensile form. As mentioned earlier in the introduction section (Section 1), the purpose of this study is to control and reduce the contraction of the stub abutment. Based on a study done by Movahedifar and Bolouri [11], by reducing the lateral displacement of the abutment, the number of rotation (lateral displacement) cycles does not affect the backpressure of the backfill. In this condition, the pressure distribution (in the wall of the abutment) is almost linear and is approximately equal to the at-rest pressure. Since the purpose of the present research is to reduce the lateral displacement of the abutment (in this situation, the number of loading cycles is not significant), the cyclic action has not been considered.

Soil will have nonlinear behavior in the case of large lateral displacements of the abutment. This behavior occurs in some cases such as the unreinforced abutment and reinforced abutment with fewer piles. However, as the number of piles increases, the lateral displacement of the abutment decreases. As a result, in such cases, the soil behavior is closer to the linear behavior. The procedure for testing is described below.

In the first test, the unreinforced abutment (in which the abutment was not connected to the pile) was subjected to the lateral load. The amount of horizontal load was increased so that the abutments head was displaced $2 \mathrm{~cm}$ under the horizontal displacement $\left(\Delta_{0}\right)$. The amount of horizontal displacement was $10 \%$ of the abutment's height. By using the instruments installed for the system, the required force for the $2-\mathrm{cm}$ horizontal displacement was obtained for the unreinforced abutment. In the subsequent test, the abutment was reinforced using a pile, i.e., the abutment was connected by a pile with a specific distance from the abutment. In this test, the reinforced abutment with a pile was subjected to the lateral force, $F_{0}$ (the same lateral force that displaced the unreinforced abutments head up to $2 \mathrm{~cm}$ ). By using an LVDT, in the system, it is possible to determine the horizontal displacement, 
(the displacement from the abutment reinforced by one pile), $\Delta_{1}$, that was caused by $F_{0}$. By comparing the values of $\Delta_{0}$ and $\Delta_{1}$, the effect of the abutmentreinforcing procedure was determined by using only one pile. During the conducted experiments for the reinforced abutment by a pile, the digital photography of the soil deformations procedure was done from the top and front view. Finally, the taken photographs were analyzed using the Geo PIV software. Using the PIV method and analysis by means of the software, the displacement vectors and shear strain diagrams of the soil (around the abutment and the pile) were obtained for the reinforced and unreinforced abutment experiments. By comparing the displacement vectors and shear strain of the soil (around the abutment and pile), for the unreinforced and reinforced piles, the stability level and active failure zone of the soil were investigated. Similar tests were carried out for the cases of the reinforced abutment with 2, 3, and 4 piles. Different plan cases of the experiments are plotted in Figure 9 which are defined as follows:

Case (A): The unreinforced abutment, in which the abutment is not connected to the pile;

Case (B): The reinforced abutment with one pile;

Case (C): The reinforced abutment with two piles;

Case (D): The reinforced abutment with three piles;

Case (E): The reinforced abutment with four piles;
Case $(\mathrm{F})$ : The reinforced abutment with one pile located between two boundary walls (i.e. between the wooden and plexiglass).

According to Subsection 3.3., the width of the pile is $6 \mathrm{~cm}$. In order to maintain the symmetry and observe the soil behavior around a pile from the plexiglass in Cases (B), (C), (D), and (E), as shown in Figure 9, the width of the piles - embedded in the boundaries - was considered as $3 \mathrm{~cm}$ (which was the half of the width of the pile far from the abutment). Hence, the piles which were only located in the set boundaries - were halved in the width dimension. In terms of loading capacity, two piles in the boundaries acted as one pile. To validate this matter, a laboratory test in which a pile with the complete width was located at the center of the set (as shown in Figure 9(f)) was used in order to compare Case $(\mathrm{F})$ with Case $(\mathrm{B})$.

First, in Cases (B), (C), (D), and (E), the reinforced abutment was subjected to lateral force $F_{0}$ to obtain horizontal displacements $\Delta_{1}, \Delta_{2}, \Delta_{3}$, and $\Delta_{4}$, and they were compared with $\Delta_{0}$ to recognize the effect of the piles on the abutment connection, through cables, on the abutment horizontal displacements. Next, in Cases (B), (C), (D), and (E), the abutment was subjected to the horizontal displacement of $2 \mathrm{~cm}$ to obtain the required force for each case. These forces $\left(F_{1}, F_{2}, F_{3}\right.$, and $\left.F_{4}\right)$ were compared with $F_{0}$ to determine and assess the effects of piles number on the required lateral force associated with the $2-\mathrm{cm}$

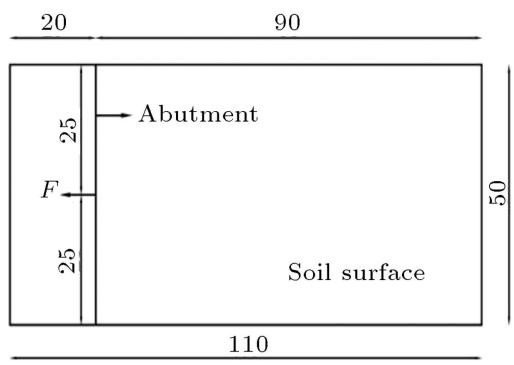

(a) Case (A)

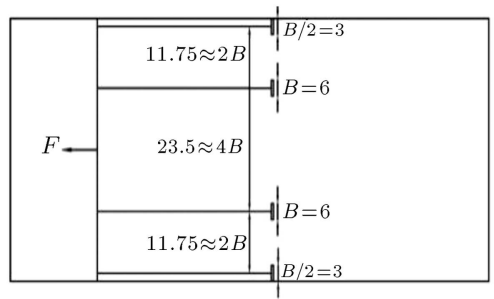

(d) Case (D)

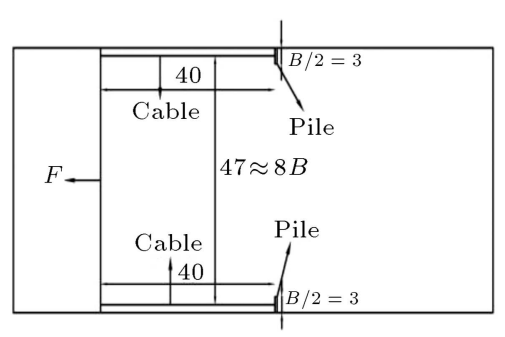

(b) Case (B)

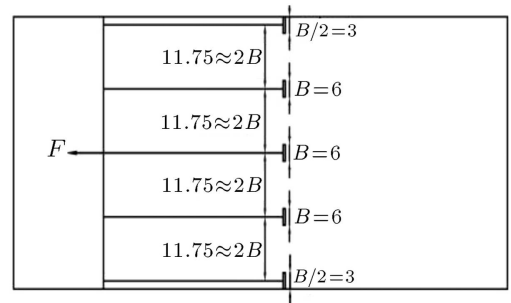

(e) Case (E)

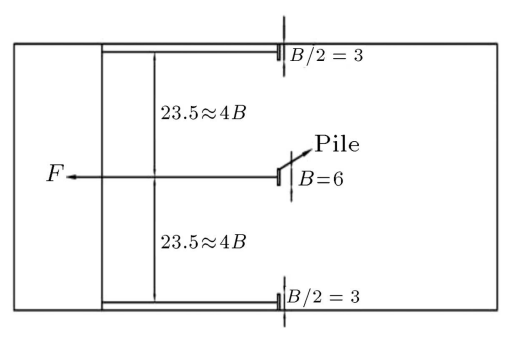

(c) Case (C)

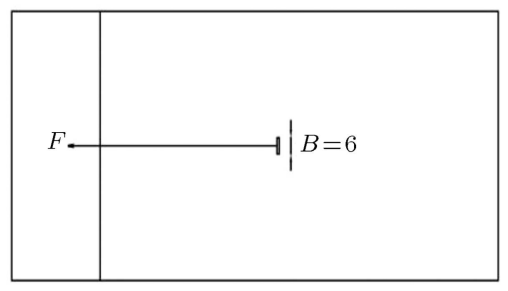

(f) Case (F)

Figure 9. (a) Case (A): The plan of the unreinforced abutment, (b) Case (B): The plan of the reinforced abutment with one pile close to plexiglass, (c) Case (C): The plan of the reinforced abutment with two piles, (d) Case (D): The plan of the reinforced abutment with three piles, (e) Case $(E)$ : The plan of the reinforced abutment with four piles, (f) Case (F): The plan of the reinforced abutment with one pile located between two boundary walls (i.e., between the wooden and plexiglass) (all units in $\mathrm{cm}$ ). 
horizontal displacement. In doing so, the pile-soil-pile interaction is illustrated.

\section{Test results and discussion}

In the following sentences, "the reinforced abutment" means that the abutment is connected to the pile(s) by the cable(s).

The described experiments in the previous section were conducted for Cases $(\mathrm{A})$ to $(\mathrm{F})$. The lateral force - exerted by an electromotor - was applied to the abutment. Then, it was applied from right to left (towards to the electromotor as shown in Figure 6(a)) in the tensile form. Finally, the experimental results were analyzed by the Geo PIV software. In all experiments, the coordinates' origin (i.e., $x=0, y=0$ ) was assumed to be on the top of the abutment (in the stationary stage, i.e., before its lateral deformation). In all experiments, in the cases of reinforced abutments, the pile(s)' distance from the abutment was selected as $40 \mathrm{~cm}$. This distance was selected in order to avoid the location of the pile(s) from the wedge failure area. If the pile is located in this zone due to the instability of this zone under the expansion and contraction of the bridge, the performance of the pile(s) lateral strength is weakened in the soil. Since the soil friction angle is of 36.3 degrees, by considering the plane failure zone, Eqs. (12) and (13) can be written in the following based on Rankine's theory:

$$
L_{\text {active }}=H \cdot \tan \left(45-\frac{\varphi}{2}\right) \text {, }
$$

if $H=20 \mathrm{~cm}$ and $\varphi=36.3$, then $L_{\text {active }}=10.12 \mathrm{~cm}$.

$$
L_{\text {passive }}=H \cdot \tan \left(45+\frac{\varphi}{2}\right)
$$

if $H=20 \mathrm{~cm}$ and $\varphi=36.3$, then $L_{\text {passive }}=39.5 \mathrm{~cm}$.

By considering Eqs. (12) and (13) and Figure 10, the active and passive wedge failures occurred at distances of $10.12 \mathrm{~cm}$ and $39.5 \mathrm{~cm}$ far from the abutment $\left(x_{\text {passive }}=39.5 \mathrm{~cm}\right.$ and $\left.x_{\text {active }}=10.12 \mathrm{~cm}\right)$, respectively.

Therefore, by locating the pile(s) $40 \mathrm{~cm}$ away from the abutment, the pile(s) was (were) not found in the passive or active wedge failure area.

The results of the experiments of Cases $(\mathrm{A})$ to $(\mathrm{F})$ are discussed under the following topics:

1. The comparison of lateral load-displacement diagrams in Cases $(\mathrm{A})$ to $(\mathrm{F})$;

2. The comparison between displacement vectors of the soil around the abutment and the pile(s);

3. The comparison of the created shear strain in the soil around the abutment and the pile(s).

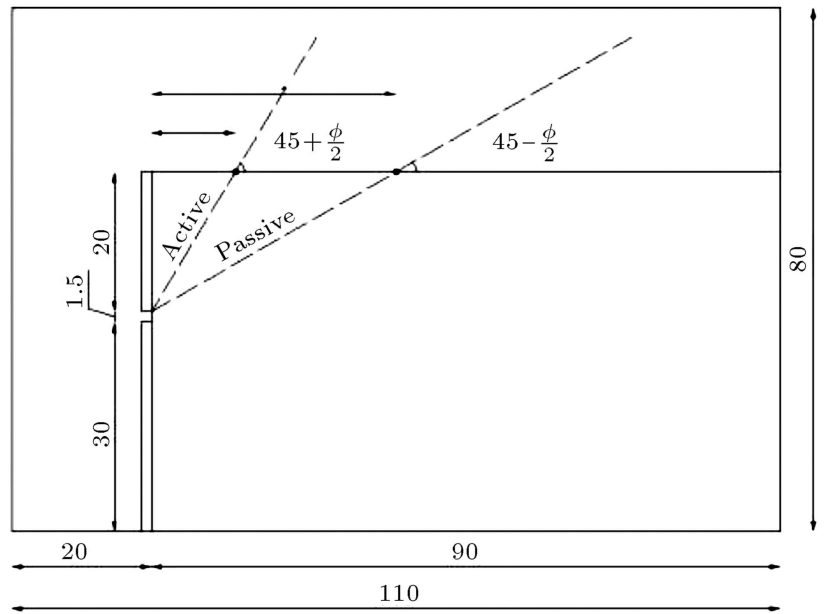

Figure 10. Active and passive failure zones of backfill (all units in $\mathrm{cm}$ ).

It should be noted that the main purpose of the present research is to investigate the soil's behavior around the stub abutment and the pile under lateral load, as discussed in Sections 5.2 and 5.3.

\subsection{Lateral load-displacement curves of an abutment}

The lateral force-displacement diagrams for abutments head are plotted by curves (a) to (f) shown in Figure 11. The plans of these cases are illustrated in Figure 9. In Figure 11, the vertical axis indicates the applied lateral load on the abutment (in Newton), and the horizontal axis shows the horizontal displacement of the abutment (in $\mathrm{mm}$ ). In all cases, the abutment was displaced $2 \mathrm{~cm}$ under the horizontal displacement, which was $10 \%$ of the abutment height. As observed in Figure 11, by increasing the lateral force, the horizontal displacement of the abutment is increased. In addition, more piles connected to the abutment by the cable(s) produce greater lateral force required for the horizontal displacement. By considering the curves in Figure 11, it is observed that, in Case (A), in order to displace

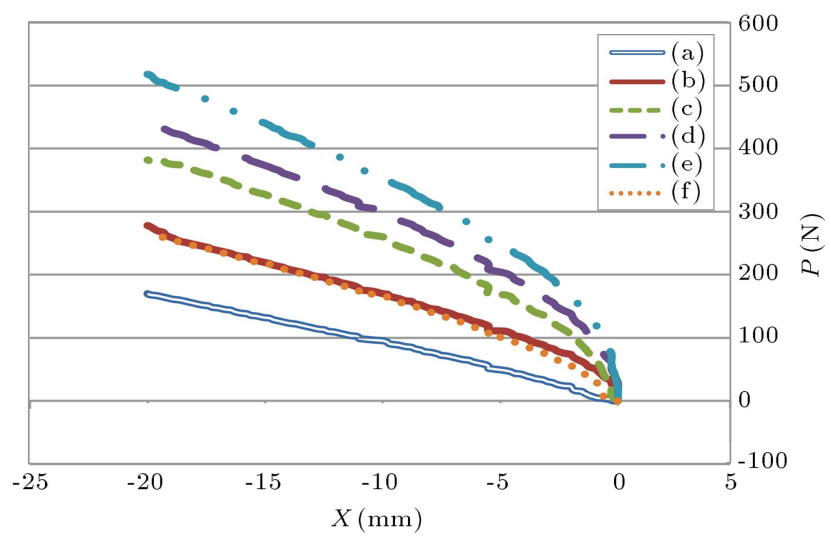

Figure 11. Curves of lateral force-displacement for the head of abutment. 
the abutment to an amount of $\Delta_{0}=2 \mathrm{~cm}$, it is necessary to apply the lateral force of $F_{0}=170 \mathrm{~N}$ to the abutment head. In other words, if the abutment is subjected to the lateral force of $170 \mathrm{~N}$, the abutment will be displaced by $2 \mathrm{~cm}$. According to curve (b) in Figure 11, for the lateral force of $F_{0}=170 \mathrm{~N}$, the abutment head had $\Delta_{1}=10 \mathrm{~mm}$ in horizontal displacement. Based on the comparison of curves (a) and (b) in Figures 11, it can be concluded that when the abutment is reinforced by a pile connected to the cable, its horizontal displacement reaches from $\Delta_{0}=$ $20 \mathrm{~mm}$ to $\Delta_{1}=10 \mathrm{~mm}$. It means that the horizontal displacement is decreased by $50 \%$, and this behavior is very productive for integral bridges. In curves (c), (d), and (e) of Figure 11, for the load, $F_{0}=170 \mathrm{~N}$, the abutment had horizontal displacements of $\Delta_{2}=$ $5.5 \mathrm{~mm}, \Delta_{3}=3.5 \mathrm{~mm}$, and $\Delta_{4}=2 \mathrm{~mm}$, respectively. According to the comparison of curves (a), (c), (d), and (e) in Figure 11, it is observed that when the abutment is reinforced by two, three, or four piles, its displacements are decreased by $72.5 \%, 82.5 \%$, or $90 \%$, respectively. By considering the above explanations, reinforcing the abutment using the pile(s) connected to the cable results in the horizontal displacement reduction under constant force. The reduction amount reaches $90 \%$. This behavior is beneficial for integral bridges; since the bridge is subjected to contraction due to the integrity of the superstructure with the abutment, the abutment moves away from the backfill and results in problems such as an active wedge failure creation in the backfill of the abutment. The active wedge failure leads to an empty zone under the approach slab that creates several problems for the bridge. After the contraction and the wedge failure, in the expansion case in the next summer season, the abutment is subjected to excessive and unpredictable stresses that cause damage to the structure of bridges. Therefore, by reinforcing the abutment with the pile(s) connected to the cable and, subsequently, by the $90 \%$ reduction of the abutment contraction, the bridge contraction is hindered considerably by this method. By preventing the bridge contraction, the wedge failure is not created in the backfill. Thus, the problems resulting from the contraction of the integral bridge are solved. According to curves (b), (c), (d), and (e) in Figure 11, when the abutment is subjected to a horizontal displacement of $\Delta_{2}=20 \mathrm{~mm}$, the amounts of required lateral force are $F_{1}=278 \mathrm{~N}, F_{2}=382 \mathrm{~N}$, $F_{3}=444 \mathrm{~N}$, and $F_{4}=517.5 \mathrm{~N}$, respectively. In other words, by increasing the number of piles, the required lateral force is increased. The experiment is carried out in Case (F), as shown in curve (f) of Figure 11, and is compared with the procedure in Case (B), as shown in curve (b) of Figure 11, to recognize the effect of boundary friction on the results. According to curve (f) in Figure 11, it is observed that the curve is very close

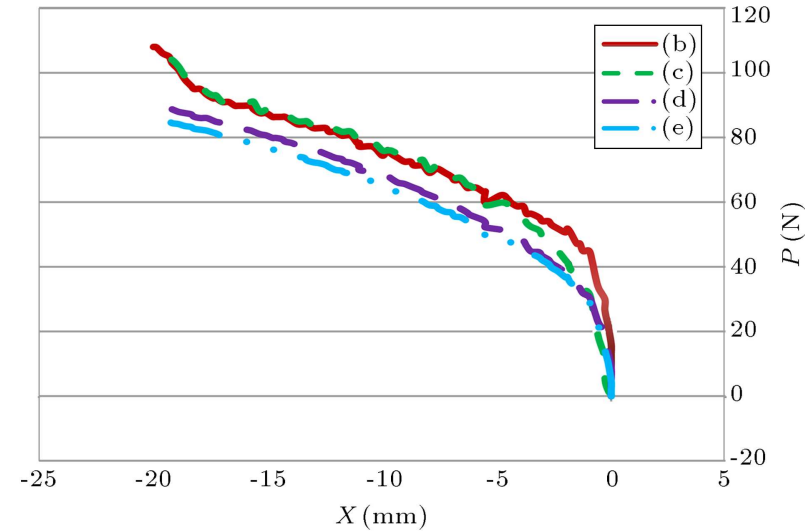

Figure 12. Curves of lateral force-displacement for the pile connected to cable.

to that in Case (B). Due to the application of special materials in the internal boundary of the plexiglass, the boundary friction does not have any sensible effect on the results.

In order to determine the effect of the soil-pile interaction on the load-bearing capacity of the piles, connected to the cable, in Cases (B), (C), (D), and (E), load-displacement diagrams were plotted for each case. By using Eq. (14), the load-displacement diagram for each pile in Cases (B), (C), (D), and (E) was extracted, as listed in Figure 12.

$$
\frac{F_{\text {Pull }}-F_{\text {abutment }}}{\text { number of piles }}=F_{\text {pile }} \text {. }
$$

$F_{\text {Pull }}$ indicates the required force to apply the lateral displacement of the abutment in the reinforced case to the pile(s), and $F_{\text {abutment }}$ indicates the required force to apply the lateral displacement in the unreinforced case. In Figure 12, the vertical axis shows the lateral force of the pile connected to the cable (in Newton), and the horizontal axis shows the horizontal displacement of the pile connected to the cable (in $\mathrm{mm}$ ). According to Figure 12, by increasing the lateral force, the horizontal displacement of the pile connected to the cable is increased. Since the distance(s) between the pile(s) in Cases (E) and (D) is less than that in the other cases, the soil-pile interaction is increased. The loaddisplacement curves related to Cases (E) and (D) are lower than the other curves. However, in Case (C), the distance between piles is longer and, thus, the lateral load-bearing capacity of each pile is increased.

\subsection{Soil displacement vectors around the abutment and buried pile}

As discussed in Section 3.4 in order to obtain the displacement vectors of the soil around the abutment and the buried pile from both the top and front views, the digital photography was conducted during each experiment and analyzed by the Geo PIV software. The 


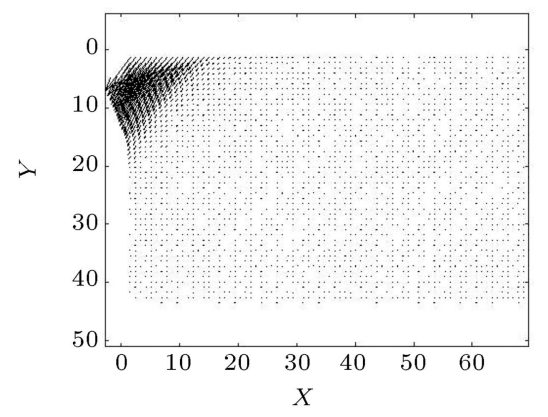

(a) Case (A)

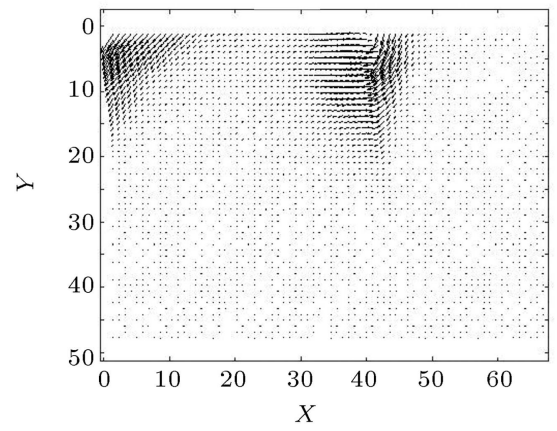

(b) Case (B)

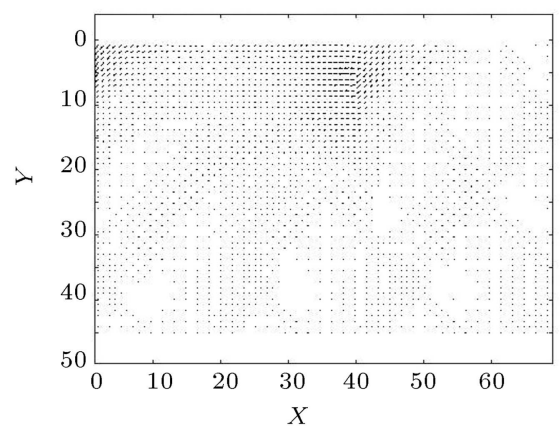

(d) Case (D)

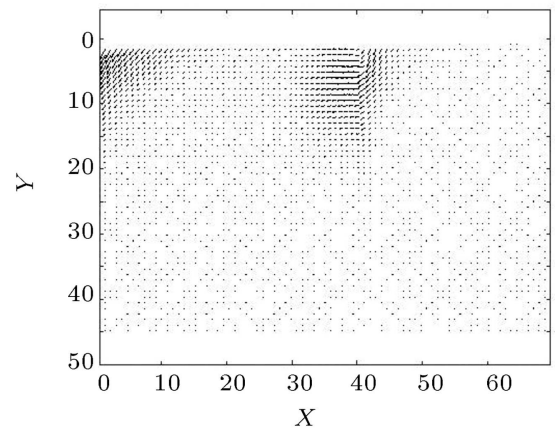

(c) Case (C)

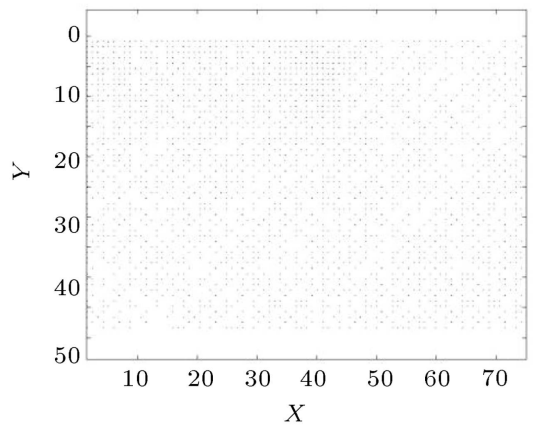

(e) Case (E)

Figure 13. Soil displacement vectors around abutment and pile for Cases (A), (B), (C), (D), and (E) (front view) (all units in $\mathrm{cm}$ ).

displacement vectors of the soil around the abutment and pile are shown in Figure 13.

In Figure 13, to ensure a better resolution of the displacement vector, the vectors are plotted with a zoom of $3 \times$. The point with the coordinates $(x=0$, $y=0$ ) shows the location of the abutment head before the deformation occurs. In the front view, in the reinforced abutment (Cases (B), (C), (D), and (E)), the piles are located in $x=40 \mathrm{~cm}$ (from the coordinate's origin). As seen in Figure 13, for all cases, the soil particles, located at a far distance from the abutment and pile, are not displaced and will remain in their initial positions. By approaching the abutment and pile location, where the soil particles are located near the pile and abutment, displacement vectors indicate more displacements than those in other positions. Therefore, the magnitude of the displacement vectors in those particles is greater than that of other positions.
According to Figure 13(a), it is observed that in the unreinforced abutment under the lateral load of $F_{0}=170 \mathrm{~N}$, the magnitude of the displacement vectors of the soil around the abutment is high. In Case (B), the abutment was subjected to the lateral load of $F_{0}=170 \mathrm{~N}$, the magnitude of displacement vectors of the soil around the abutment is lower than that in Case (A). However, some large displacement vectors under the lateral load were created around the pile. In Case $(\mathrm{C})$, the abutment is subjected to the lateral load of $F_{0}=170 \mathrm{~N}$, and the magnitude of the displacement vectors of the soil around the abutment is lower than those in Cases (A) and (B); in addition, the magnitude of the displacement vectors around the pile under the lateral load is lower than that in Case (B). In Cases (E) and (D), the abutment is subjected to the lateral load of $F_{0}=170 \mathrm{~N}$. The magnitude of the displacement vectors of the soil around the 


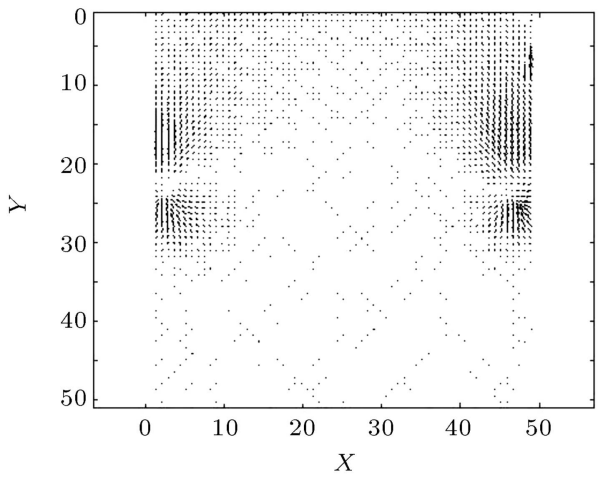

(a) Case (B)

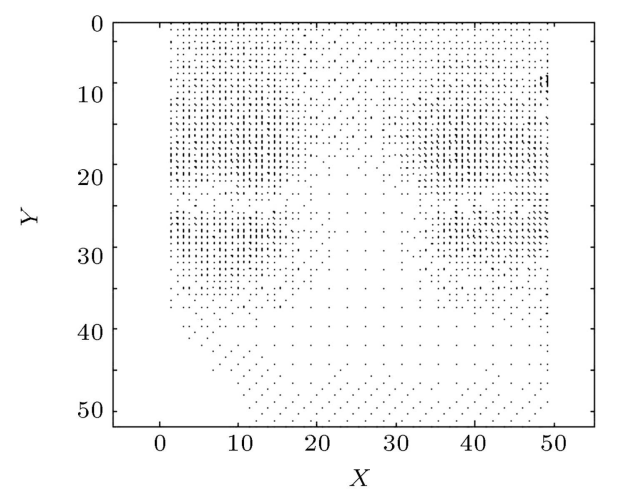

(c) Case (D)

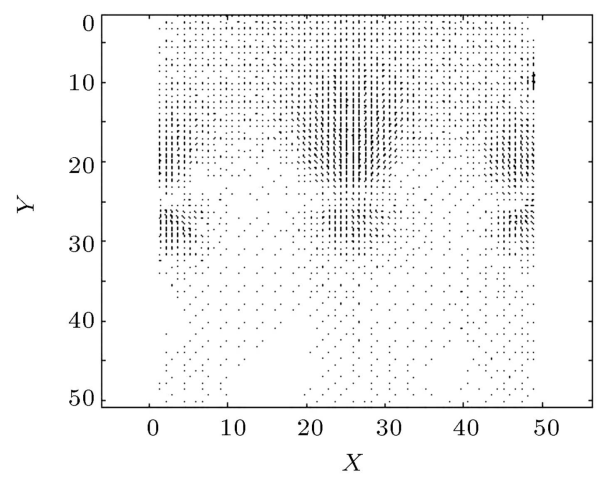

(b) Case (C)

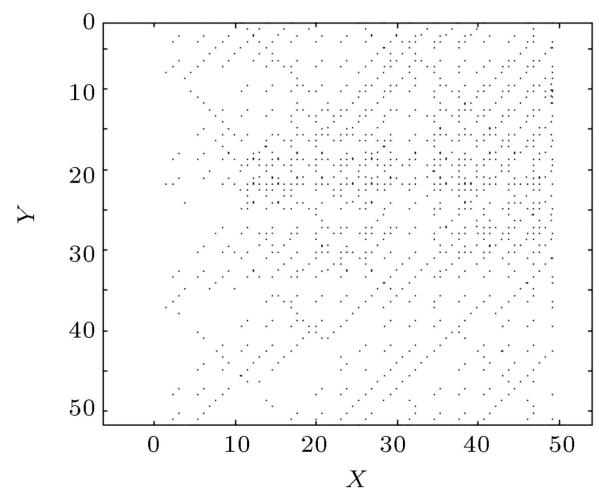

(d) Case (E)

Figure 14. Soil displacement vectors around abutment and pile for Cases (B), (C), (D), and (E) (top view) (all units in $\mathrm{cm}$ ).

abutment is lower than those in Cases (A), (B), and (C). The magnitude of the displacement vectors around the pile under the lateral load is lower than those in Cases (B) and (C). Therefore, when the number of reinforcing piles increases, the magnitude and depth of the displacements of the soil around the abutment and pile decrease. Even in Case (E), the displacement of the soil around the abutment and pile approaches the very small amount. This behavior is very beneficial in integral bridges, because in this behavior, in the contraction of the bridge, the active wedge is not created in the soil behind the abutment. Hence, the most important problem of integral bridges is solved. According to different cases of Figure 13, it is observed that by reinforcing and increasing the number of piles, displacements on the soil surface are decreased. Even in Case (E), the displacement on the soil surface approaches zero. This behavior is the reason why that the damage to the topside of the bridge adjacent to soil does not take place. This is also very useful for integral bridges. The investigation of the interaction between the pile and soil, based on different cases of Figure 13, indicates that the soil particles located on the right side of each pile move downwards with the steep angle, while the soil particles on the left side are displaced upwards with a salient angle. This procedure is normal, according to the applied direction of the lateral force.

Another observation is that the maximum hori- zontal displacement occurs in the pile and abutment head and decreases with depth. At low depths, the displacements of soil around the pile and abutment are very small. In addition, it is observed that the horizontal displacements of soil particles in front of the pile are larger than the vertical ones. Vertical displacements occurred on the soil surface in front of the pile, which exerted great effect on pile displacement. Therefore, investigating the vertical displacement of the soil in front of the pile is very important. Such a conclusion was extracted from Hajialilue et al. [35] research; hence, it can be cited as a general conclusion in soil behaviorism.

The displacement vectors of the soil around the piles, from the top view, for Cases (B), (C), (D), and (E) are listed in Figure 14 in order to investigate the interaction of the piles with each other.

In Figure 14, these vectors are plotted with $3 \times$ zoom to observe a better resolution of displacement vectors. To investigate the deformations around the piles and displacement vectors, a $50-\mathrm{cm}$ plan of the set (in which the piles exist) was extracted, as plotted in Figure 14. In this figure, in Cases (B), (C), (D), and $(\mathrm{E})$, the row of piles is defined to be placed in $x$ direction, and the load is applied in $y$ direction in the weak axis of piles. In all cases, the piles are located on the axis of $y=25 \mathrm{~cm}$. According to Figure 14, in all cases, soil particles, far away from the piles, 
were not displaced. Therefore, the magnitude of the displacement vectors related to these particles was zero. However, in the location of piles, the soil particles located near the piles indicated great displacement so that the magnitude of the displacement vectors of these particles was large. For Cases (B) and (C), Figure 14 indicates that the soil displacements in the load direction are larger than those in the perpendicular direction of the applied load. If the reinforcing piles are placed in one row, it is recommended that the direction of the wrapping piles be located perpendicular to the load direction. In this way, by increasing the number of piles (and, thus, decreasing the distance between them), the interaction of the piles is decreased. As a result, the loading capacity of the piles is increased. Therefore, in this study, the direction of the piles' location was chosen to be perpendicular to the load direction. According to Cases (B), (C), (D), and (E), the more the number of the piles there are, the less the field and magnitude of displacement occur around the piles (in constant force). In these cases, the piles have lower interaction with each other, resulting in the better performance of all piles. Thus, in Case (E), the displacement of the soil around the piles is so small (almost zero). Therefore, this behavior is useful for the soil adjacent to the bridge and hinders the destruction of the superstructure.

\subsection{Shear strains around the abutment and buried piles}

Figure 15 indicates the shear strain of the soil around the abutment and buried pile (from the front view).

The coordinate point of $(x=0, y=0)$ shows the location of abutment's head before the deformation occurs. In the reinforced abutment (i.e., Cases (B), (C), (D), and (E)), the pile(s) is (are) located at $x=$ $40 \mathrm{~cm}$. The colorful bands, which are shown in all figures, indicate the limit of shear strains.

As observed in Figure 15, for all cases, the shear strain of the soil around the abutment and pile is high. The created shape of shear strain wedge is triangular in 2D (in front view). As seen in Figure 15, Case (A), in the unreinforced abutment which is subjected to the lateral load of $F_{0}=170 \mathrm{~N}$, the shear strain around abutment is high, and the maximum value of shear strain in this area is about 0.8. In Case (B), the abutment is subjected to the lateral load of $F_{0}=170 \mathrm{~N}$, the amount of shear strain of the soil around the abutment is less than that in Case (A), and its maximum value is about 0.5 . On the other hand, in this case, in the soil around the pile, high shear strain occurred such that its maximum value was about 2.5. It means that when the abutment is reinforced by a pile, the value of shear strain in the soil around the abutment is decreased by $40 \%$; however, in the soil around the pile, the high shear strain is created. In Case (C), the abutment was subjected to the lateral load of $F_{0}=170 \mathrm{~N}$. The amount of maximum shear strain around the abutment was about 0.15 , which was less than that in Cases (A) and (B). The amount of the shear strain in the soil around the pile was about 1, which was less than that in Case (B). In Cases (E) and (D), the abutment was subjected to the lateral load of $F_{0}=170 \mathrm{~N}$. The amount of maximum shear strain in the soil around the abutment for Case (D) was about 0.07 and, for Case (E) was about 0.01 which was less than that in Cases (A), (B), and (C). The amount of maximum shear strain in the soil around the pile for Case (D) was about 0.5 and, for Case (E) was about 0.08 that was less than that in Cases (B) and (C). When the abutment was reinforced by 1, 2, 3, and 4 piles connected to the cables, the amount of shear strain in the soil around the abutment was reduced by $40 \%, 81 \%, 91 \%$, and $99 \%$, respectively. This behavior is useful for integral bridges and solves the problems for the contraction of integral bridges. If the amount of shear strain in the soil around the abutment is reduced, the wedge failure is not observed in the soil.

When the abutment was reinforced by a pile (Case (B)), the maximum shear strain in the soil around the pile was about 2.5. However, when the abutment was reinforced by 2,3 , and 4 piles connected to the cables (Cases (C), (D), and (E)), the amount of maximum shear strain in soil around the pile was reduced by $60 \%, 80 \%$, and $97 \%$, respectively. This behavior is so beneficial for the soil around the integral bridge under contraction.

Due to the lateral load direction (which is from right to left), the shear strain area does not have a regular form towards the pile location and is inclined to the left. However, the shear strain made in the soil behind the pile (right side of the pile) is more than that in front of the pile (left side of the pile). Such a conclusion was extracted from Hajialilue et al. [35] research; hence, it can be cited as a general conclusion in soil behaviorism.

In order to investigate the interaction of the piles, the shear strain of the soil around the piles, from the top view, was considered for Cases (B), (C), (D), and (E) (shown in Figure 16).

The coordinate axes and the direction of the piles' location in Figure 16 are the same as those in Figure 14. According to Figure 16 and Cases (B), (C), (D), and (E) (from the top view), it can be observed that the back and front of the pile area (in which the shear strain occurred on it) has a circular shape. In front of the pile, there was an area where a pile under the lateral load moved in its direction. The back zone was considered as the area where a pile under the lateral load moved away from it. According to Figure 16, the circular area that was created in the front zone of the pile was larger 


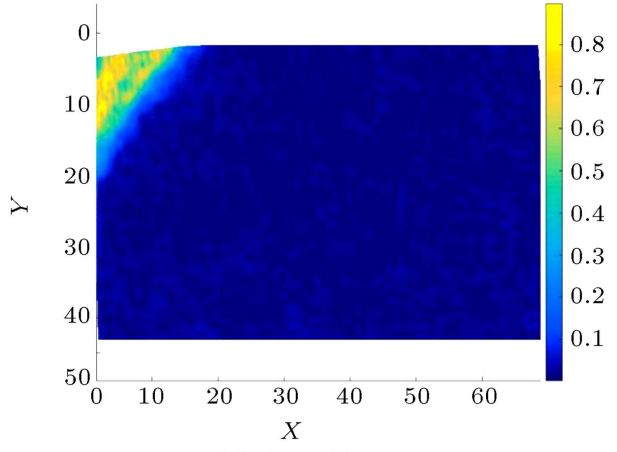

(a) Case (A)

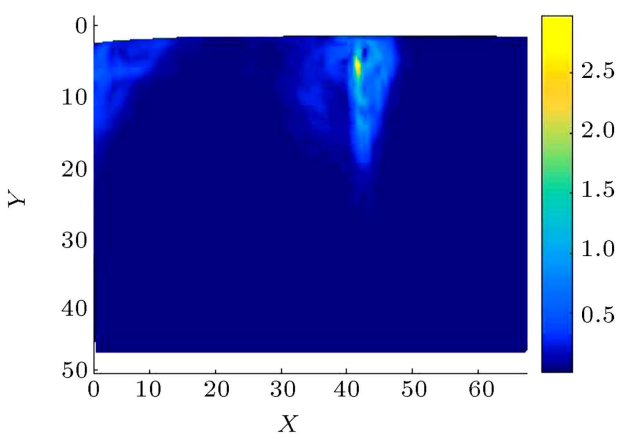

(b) Case (B)

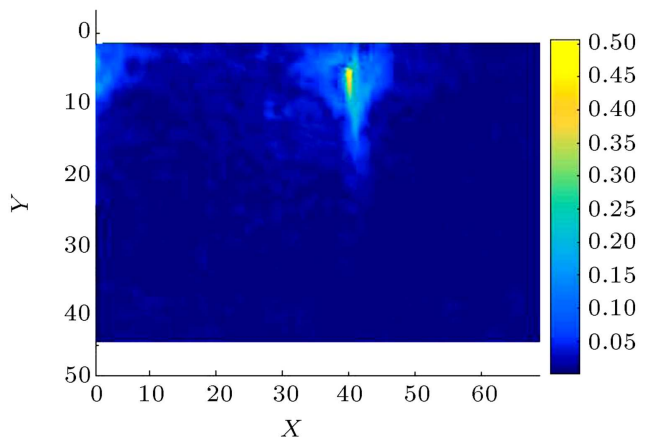

(d) Case (D)

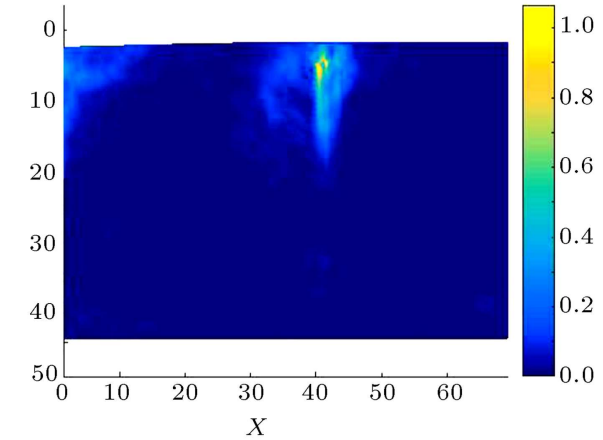

(c) Case (C)

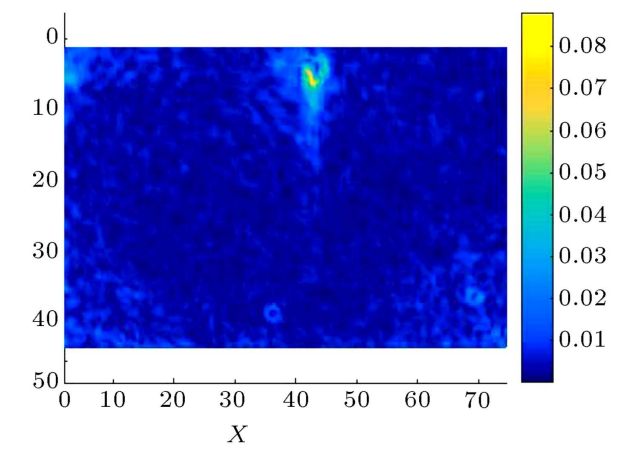

(e) Case (E)

Figure 15. Soil shear strain around abutment and pile for Cases (A), (B), (C), (D), and (E) (front view) (all units in cm).

than the circular zone related to the back area of the pile. When these 2D circular and triangular areas were combined (in Figure 15), a conical shape was formed in the three-dimensional space. Therefore, the failure area of the active and passive zones was conical in shape, as approved by the latest studies [35]. Hajialilue et al. [35] concluded that the shape of the wedge failure around the pile under the lateral load was conical by examining the behavior of the soil around the pile under the lateral load. The schematic diagram of the wedge failure, achieved by using the PIV method, is shown in Figure 17. In the present study, by examining the shear strain diagrams from the top view (Figure 15) and the front view (Figure 16) and their combination, it is shown that the shape of the failed wedge is conical. Therefore, by comparing the results of this research and the research done by Hajialilue et al. [35], a general conclusion in soil behaviorism is obtained, which is the conical shape of the failed wedge in the soil around the pile under the lateral load.

According to Figure 16 and Cases (B), (C), (D), and $(\mathrm{E})$, it is observed that by increasing the number of piles, the amount of shear strain on the soil is decreased considerably so that the amount of maximum shear strain on the soil in Case (B) is about 0.5. However, the amount of shear strain on the soil in Case (E) is about 0.04 , which is a very low value and indicates the reduction by about $92 \%$. In other words, by increasing the number of reinforced piles for the integral bridge, the amount of shear strain on the soil is decreased considerably. This behavior is useful for the pavement above the pile. 


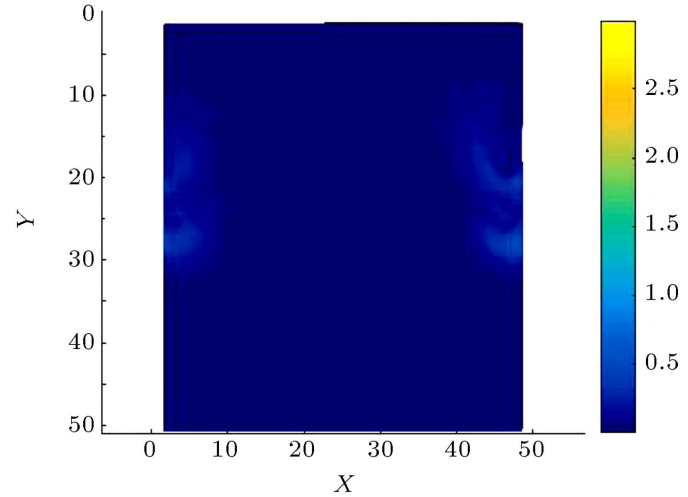

(a) Case (B)

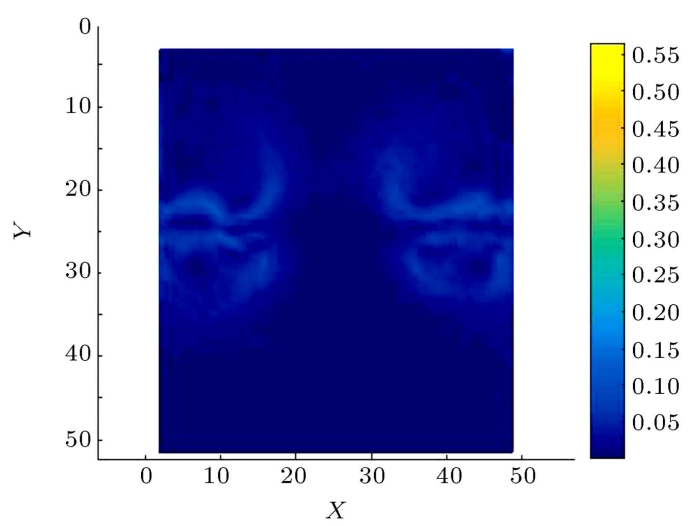

(c) Case (D)

Figure 16. Soil shear strain around pile for Cases

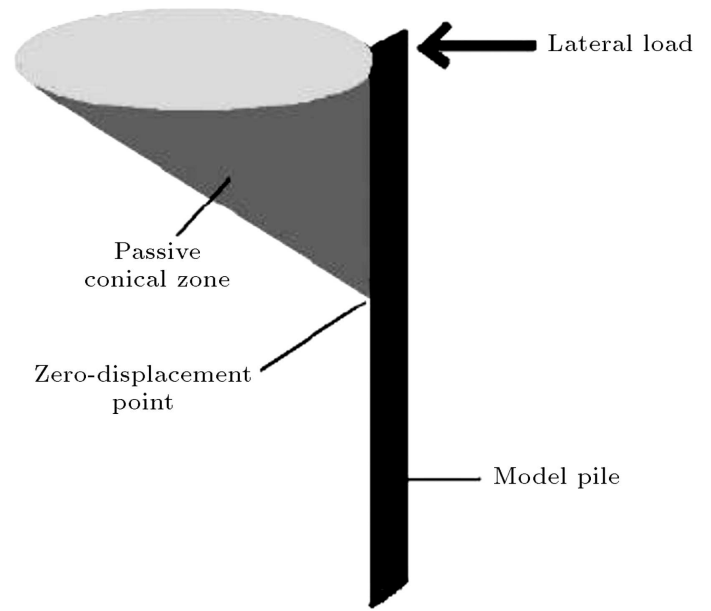

Figure 17. Proposed 3D model of passive zone of soil [35].

\section{Summary and conclusions}

The effects of an integral stub abutment bridge reinforced by a pile, connected to the cable to hinder the contraction of an integral bridge, were investigated by modeling it in the laboratory. Then, the models were analyzed. Since the most important issue of integral bridges is the soil behavior around the bridge, in this

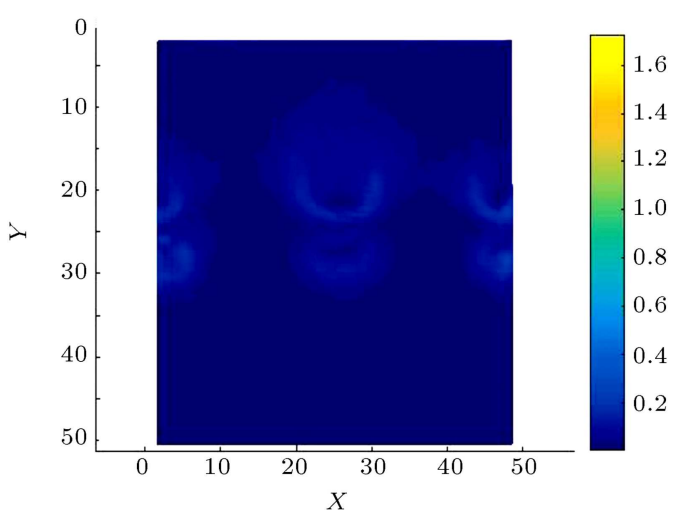

(b) Case (C)

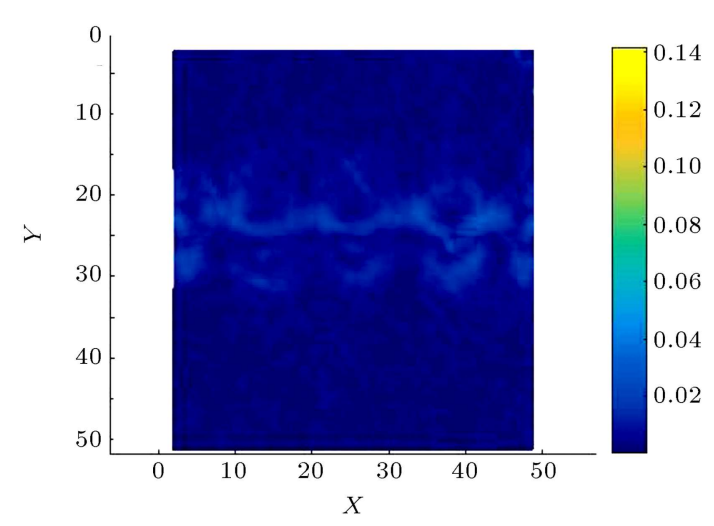

(d) Case (E)

(B), (C), (D), and (E) (top view) (all units in cm).

research, the PIV method was used for conducting experiments. In this method, soil behavior around stub abutment can be investigated. By investigating the results of the experiments of reinforcing an abutment by a pile connected to the cable(s), the following results can be concluded:

- The lateral displacement of the abutments head was hindered considerably. By increasing the number of reinforced piles, the magnitude of the lateral displacement was decreased; accordingly, when the abutment was reinforced by four piles connected to cables, the magnitude of the lateral displacement of the abutment's head was decreased by about $90 \%$;

- The magnitude of the displacement vectors of the backfill decreased considerably; increasing the number of piles caused lower displacement of the backfill;

- In the soil around the pile, the displacement was created. When the number of the piles was increased, the magnitude of soil displacement around the pile was decreased;

- The shear strain created in backfill was decreased considerably such that increasing the reinforced piles led to lower shear strain;

- In soils around the pile, the shear strain was created 
when the number of reinforced piles was increased; the amount of the shear strain of the soil around the pile was decreased. In addition, the failure area of the active and passive zones (in soils around the pile) has a conical shape.

The contraction of integral bridges is one of the most important problems of integral bridges so that, during the bridges contraction, the abutment will move far from the backfill. This leads to the active pressure in the backfill behind the abutment. The active pressure created in the backfill leads to active wedge failure. This wedge failure makes many problems in the bridge including the empty area under an approach slab. Therefore, excess and unpredictable forces on the abutment occurred. In this study, by using the pile, the lateral displacement of the abutment was controlled against the force (due to the bridge contraction). Therefore, the magnitude of displacement vectors and shear strains of the soil around the abutment sharply decreased. Therefore, wedge failure in the backfill was prevented. In this way, the problems caused by the wedge failure in the backfill of the integral abutment bridge were eliminated. In this research, granular soil behavior was investigated. The results of this research are limited to these soils.

\section{References}

1. Khodair, Y.A. and Hassiotis, S. "Analysis of soil-pile interaction in integral abutment", Journal of Computers and Geotechnics, 32(3), pp. 201-209 (2005).

2. Dicleli, M. "Simplified model for computer-aided analysis of integral bridges", J. Bridge Eng., ASCE, 5(3), pp. 240-248 (2000).

3. Thevaneyan, K.D. and Forth, J.P. "Soil-structure interaction of integral abutment bridge", Proc., Int. Conf. on Structural Engineering Construction and Management (ICSEM 2011), Univ. of Peradeniya, Peradeniya, Sri Lanka, pp. 9-20 (2011).

4. Comisu, C.C. "Integral abutment and jointless bridges", Bulletin of the Polytechnic Institute of Jassy, 63(67), pp. 107-118 (2005).

5. Pak, D., Bigelow, H., and Feldmann, M. "Design of composite bridges with integral abutments", Steel Construction, 10(1), pp. 23-30 (2017).

6. Cooke, R.S. "The concept and construction of integral bridge", Seminar on Design and Construction of Integral Bridges, Jabatan Kerja Raya, Kuala Lumpur, Malaysia (2003).

7. Thevaneyan, D., John, P., and Jianqiao, Y. "Superstructure behavior of a stub-type integral abutment bridge", J. Bridge Eng., ASCE, 19(3), pp. 1-12 (2014).

8. Arsoy, S., Baker, R., and Duncan, J. "The behavior of integral abutment bridges", Rep. VTRC 00CR3, Virginia Transportation Research Council, Charlottesville, VA (1999).
9. Marques Lima, J. and De Brito, J. "Inspection survey of 150 expansion joints in road bridges", Engineering Structures, 31(5), pp. 1077-1084 (2009).

10. Bigelow, H., Pak, D., Hoffmeister, B., Feldmann, M., Seidl, G., and Petraschek, T. "Soil-structure interaction at railway bridges with integral abutments", Procedia Engineering, 19(9), pp. 2318-2323 (2017).

11. Movahedifar, M. and Bolouri, J. "An investigation on the effect of cyclic displacement on the integral bridge abutment", Journal of Civil Engineering and Management, 20(2), pp. 256-269 (2014).

12. Barr, P., Halling, M., Huffaker, C., and Boyle, H., Behavior and Analysis of an Integral Abutment Bridge, Bridges Transportation Research Board, pp. 21-41, Logan, Utah (2013).

13. Kong, B., Cai, C.S., and Kong, X. "Thermal property analysis and applications of GFRP panels to integral abutment bridges", Engineering Structures, 76, pp. 19 (2014).

14. Peric, D., Miletic, M., Shah, B., Esmaeily, A., and Wang, H. "Thermally induced soil structure interaction in the existing integral bridge", Engineering Structures, 106(1), pp. 484-494 (2016).

15. Arsoy, S. "Experimental and analytical investigation of piles and abutment bridges", PhD Thesis, Virginia Polytechnic Institute and State University, USA (2000).

16. Horvath, J.S. "Integral - Abutment bridges: problems innovative solutions using EPS geofoam and other geosynthetices", Manhattan College Research Report No. CE/GE-00-2, pp. 1-15, New York, U.S.A. (2000).

17. Dicleli, M. and Albhaisi, S.M. "Performance of abutment backfill system under thermal variations in integral bridges built on clay", Engineering Structures, 26(7), pp. 949-962 (2004).

18. Zordan, T., Briseghella, B., and Lan, C. "Parametric and pushover analyses on integral abutment bridge", Engineering Structures, 33(2), pp. 502-515 (2011).

19. Zordan, T., Briseghella, B., and Lan, C. "Analytical formulation for limit length of integral abutment bridges", Structural Engineering International: Journal of the International Association for Bridge and Structural Engineering (IABSE), 21(3), pp. 304-310 (2011).

20. Kim, W. and Laman, J.A. "Numerical analysis method for long-term behavior of integral abutment bridges", Engineering Structures, 32(8), pp. 2247-2257 (2010).

21. Keisha, T., Kim, W., and Laman, J.A. "Parametric study and length limitations for prestressed concrete girder integral abutment bridges", Structural Engineering International, 2, pp. 21-34 (2011).

22. Kong, B., Cai, C.S., and Zhang, Y. "Parametric study of an integral abutment bridge supported by prestressed precast concrete piles", Engineering Structures, 120, pp. 37-48 (2016). 
23. Olsong, S.M., Long, J.H., Hansen, J.R., Renekis, D., and LaFave, J.M. "Modification of IDOT integral abutment design limitation and details", Illinois Center for Transportation, Report No.09-054UILU-ENG2009-2035, University of Illinois at Urbana-Champaign (2009).

24. Civjan, S.A., Bonczar, C., Brena, S.F., DeJong, J., and Crovo, D. "Integral abutment bridge behavior: Parametric analysis of a Massachusetts bridge", $J$. Bridge Eng., ASCE, 12(1), pp. 64-71 (2007).

25. Ooi, P.S., Lin, X., and Hamada, H.S. "Numerical study of an integral abutment bridge supported on drilled shafts", J. Bridge Eng., ASCE, 13(5), pp. 1931 (2010).

26. Dicleli, M. and Erhan, S. "Effect of soil-bridge interaction on the magnitude of internal forces in integral abutment bridge components due to live load effects", Engineering Structures, 32(1), pp. 129-145 (2010).

27. Huang, J., Shield, C.K., and French, C.E. "Parametric study on concrete integral abutment bridge", J. Bridge Eng., ASCE, 13(5), pp. 511-526 (2008).

28. Dicleli, M. and Albhaisi, S. "Maximum length of integral bridges supported on steel H-piles driven in sand ", Engineering Structures, 25(1), pp. 1491-1504 (2009).

29. Tatsuoka, F., HenryMun, N., Tetsuya, K., Nishikiorid, H., Somae, R., Kiyotaf, T., Tateyamag, M., and Watanabeg, K. "Stability of existing bridges improved by structural integration and nailing", Soils and Foundations, 52(3), pp. 430-448 (2012).

30. Koseki, J., Munaf, Y., Tatsuoka, F., Tateyama, M., Kojima, K., and Sato, T. "Shaking and tilt table tests of geosynthetic - reinforced soil and conventional - type retaining walls", Geosynthetics International, 5(2), pp. 73-96 (2011).

31. Tatsuoka, F., Tateyama, M., Koda, M., Kojima, M., Yonezawa, T., Shindo, Y., Tamai, S. "Research and construction of geosynthetices-reinforced soil integral bridges", Transportation Geotechnics, 8, pp. 4-25 (2016).

32. Rollins, K.M., Olsen, R.J., Egbert, J.J., Jensen, D.H., Olsen, K.G., and Garrett, B.H. "Pile spacing acts on lateral pile group behavior: Load tests", Journal of Geotechnical and Geoenvironmental Engineering, 132(10), pp. 1262-1271 (2006).

33. Wood, D.M., Geotechnical Modeling, John Wiley \& Sons, Spon Press, London and New York (2004).
34. White, D.J., Take, W.A., and Bolton, M.D. "Soil deformation measurement using particle image velocimetry (PIV) and photogrammetry", Geotechnique, 53(7), pp. 619-631 (2003).

35. Hajialilue, M., Sojoudi, Y., and Azarnya, H. "Soil deformation pattern around laterally loaded piles", International Journal of Physical Modeling in Geotechnics, 11(3), pp. 116-125 (2011).

\section{Biographies}

Majid Barghian was born in Tabriz, Iran in August 1959. He received the BSc degree in Civil Engineering from University of Tabriz, Tabriz, Iran in 1986. He also received the MSc and $\mathrm{PhD}$ degrees in Structural Engineering from University of Manchester Institute of Science and Technology (UMIST), UK in 1988 and 1997, respectively. He is currently an Associated Professor. He has authored three books in Bridge Engineering area. He has authored or coauthored several papers in journals and in national and international conference proceedings. His current research interests include bridge engineering and nonlinear systems.

Saeed Khaki Khatibi was born in Tabriz, Iran on May 10, 1986. He received the BSc and MSc degrees in Civil Engineering and Soil Mechanics Engineering from University of Tabriz, Tabriz, Iran in 2009 and 2011, respectively. He is currently a PhD student in University of Tabriz, Tabriz, Iran.

Masoud Hajialilue-Bonab received the BSc degree in Civil Engineering from University of Tabriz Iran in 1994 and MSc degrees in Structural Engineering from Sharif University of Technology in 1996. He received his $\mathrm{PhD}$ degree in Geotechnical Engineering from University of Caen and LCPC-France in 2002 and worked as a Research Associate in Cambridge University for couple of years. $\mathrm{He}$ is currently a Professor of Geotechnical Engineering at University of Tabriz, and his main research focuses on physical modeling of geotechnical system. He is the author of sixty national and international peer-reviewed journal papers and over ten national and international research reports. 